\section{P-155 MOUNTBATTEN INTRANET - REDUCING THE CLICKS}

Duncan Fleming. Mountbatten Hospice, Newport, UK

10.1136/spcare-2021-Hospice.171

Background The existing Mountbatten intranet site had become outdated and was not user friendly. Employees were struggling to find important documents, this was leading to confusion, inefficiencies, mistakes and discontent.

Aims The vision for our new intranet site was that it would be a central hub where employees would find everything they needed in one location, providing transparency. It would be an interface where they would access all systems and files alongside regular communications, policies, risk assessments, audits, meetings paperwork, guidance in a knowledge base area... and a buy and sell Mountbatten Bay function.

Method A working party was established and the first task was to identify a preferred platform to host the site. The group then looked at the content and layout in consultation with representatives from across all departments. Once this was agreed the focus turned to building the site and then training. The final stage was to support employees with file migration to the new site using a metatag function. A feedback survey is available on the site which employees use to make suggestions for additional content or to recommend changes.

Results The aims of the project have been achieved. Mountbatten's employees access all files and systems they need in their roles via the new site. All policies, risk assessments and meetings paperwork can be easily retrieved using metatags and a fresh design including news sliders has been well received. The site has delivered a transparency across the organisation and its two hospices which did not exist prior to the launch.

Conclusion The intranet is now the heartbeat of Mountbatten; transparency of the organisation's information is at its core. It is a great example of an IT system supporting clinical and non-clinical employees in their roles and helps to achieve consistency, efficiency and trust.

\section{P-156 CAN A HOSPICE EMBARK ON A JOURNEY OF DIGITAL TRANSFORMATION DURING AND AFTER A PANDEMIC? YES}

Sophy Horner, Sue McGraw, Maddy Bass. St John's Hospice, Lancaster, UK

\subsection{6/spcare-2021-Hospice.172}

When you send over a hundred staff to work from home equipped with pens, paper notepads plus a handful of laptops, you know your technology and digital infrastructure is weak and could hamper your ability to respond effectively. It was time to seek support from the local health economy.

The aim of our Digital Transformation Programme is to maximise the momentum for change to support digital transformation that 'builds back better' by empowering staff, patients, their families, governance and health partners. The journey started by collaborating with external colleagues and procuring the services of an external consultant to ensure an 'outside-in' perspective. A migration to Office 365 was followed by purchasing laptops for community use e.g. clinical staff working in patients' homes. Digital communications and fundraising were used to reach out to the community.

In practice Office 365 has seen staff engaging 'face to face' via 'Teams' and improved our cyber security processes. New technology is resulting in films e.g. to support care home staff, patients and recruitment, with one film receiving over 15,000 views. The experience of successful (at times frustrating) digital fundraising led the hospice to a new website and an investment in Donorflex to influence future income generation decisions.

Our topical journey also sees us using existing systems differently to streamline processes, clarify protocols and work more efficiently. Staff are open to change and more willing to voice their needs so current activities include plans for staff digital upskilling, collaboration with the local university, the imminent arrival of our Telephony System Replacement, delivery of podcasts and exploration of virtual consultations. The recruitment of a Digital Transformation Manager to help build prowess for a 21st century hospice supported by the recently formed Digital Transformation Working Group will facilitate our continuing journey and ensure all departments have ownership.

\section{P-157 CAMPAIGNING FOR INCREASED END-OF-LIFE FUNDING FROM LOCAL HEALTH BUDGETS}

Helen Furnivall. Ashgate Hospicecare, Chesterfield, UK

\subsection{6/spcare-2021-Hospice. 173}

Background Prior to the pandemic outbreak, Ashgate Hospicecare had been in protracted discussions with the CCG for increased funding for months. We had a $£ 2$ million budget deficit that was no longer sustainable, and for us to survive, the local health system needed to make a larger financial contribution.

Aims Mobilise community support behind a campaign to persuade the CCG to award Ashgate a funding increase, so that compulsory job cuts during a pandemic could be avoided whilst securing our future.

Methods Case studies of families we had helped were central to the campaign and used across all channels, including via videos on social media. We highlighted the importance of end-of-life care through national media, including a visit to the hospice from Radio 4's Chris Vallance and on Radio 5 Live, which led to hospice funding being raised in the House of Lords. We urged people to write to their MP and estimate over 100 supporters did so. We also had meetings with North Derbyshire's MPs, many of whom advocated on our behalf.

Results In November, we were delighted to reveal we had secured an increased funding settlement from the CCG, which meant we would not have to reduce our services or make job cuts. Our communications team worked with them to issue a statement and the news was covered extensively in the media.

Conclusions We believe our campaign could be useful for other hospices facing serious funding challenges. We will continue to campaign for a greater proportion of end-of-life funding from health budgets rather than fundraising, which the past year has shown us can be so precarious. 